\title{
Analysis of Surface Temperature Measurements over Complex Urban Sites
}

\author{
Zsuzsanna Dezső ${ }^{A^{*}}$, Rita Pongrácz ${ }^{\mathrm{AB}}$, Judit Bartholy ${ }^{\mathrm{AB}}$ \\ Received: October 31, 2019 | Revised: December 29, 2019 | Accepted: December 30, 2019 \\ DOI: $10.5937 / g p 23-23844$
}

\begin{abstract}
The aim of this study is to analyse the thermal properties of natural and artificial urban surfaces and the impact of surface colours and shading. Measuring campaigns were conducted in spring and summer (2018-2019) in the district XI of Budapest to determine the surface temperature of various urban materials. The results show that the coolest surfaces are natural covers (water, vegetation), while the hottest surfaces are concrete pavements, asphalt and rubber paving when exposed to direct solar radiation. Moreover, among concrete pavements, light coloured surfaces warm up $5-6^{\circ} \mathrm{C}$ less on average compared to dark coloured surfaces. The use of rubber paving may be disadvantageous from the urban climatological point of view, as these surfaces become extremely hot under sunny conditions.
\end{abstract}

Keywords: surface temperature measurements; concrete pavements; rubber paving; outdoor thermal comfort; Budapest

\section{Introduction}

It is a well-known fact that in urban areas, human activities result in special climatic conditions. Urban climate studies nowadays are becoming more and more important as their results can be directly utilized by urban planners (e.g. Nevat et al., 2020), architects (e.g. Beniassadi et al., 2019) and municipal decision-makers (e.g. Zen et al., 2019). In the framework of a long-term cooperation between the Urban Climate Research Group of the Department of Meteorology at the Eötvös Loránd University (Budapest) and the Department of Environment at the Municipality of Ujbuda (district XI of Budapest), regular urban climate measurements are carried out in the district XI of Budapest to detect the urban heat island (UHI) effect on different spatial scales.

Measuring campaigns were conducted in July 2018 and later, in May and June 2019 to determine the surface temperature of various urban materials using an infrared thermometer. The purpose of these measurements was to obtain information about the thermal properties of different urban surfaces, objects (covering materials, walls, pavements, etc.) in order to analyse which surfaces are suitable for decreasing and hence mitigating the UHI effect. The impact of the colour of different surfaces and the role of shading are analysed as well.

One of the most often analysed phenomena related to cities is the UHI effect (e.g. Sundborg, 1950; Oke, 1982). The main causes of the UHI-generating heat surplus are associated with the different structure, land cover materials and greenness of urban and rural areas. In addition, heat and moisture release due to human activities plays an important role, too. The effect of this extra warmth on human comfort depends on the season and the climatic location of the city. In the cold season or in a city with a relatively cold cli-

\footnotetext{
A Eötvös Loránd University Department of Meteorology, Pázmány Péter sétány 1/A, H-1117 Budapest, Hungary; e-mails: dezsozsuzsi@caesar.elte.hu, prita@nimbus.elte.hu, bartholy@caesar.elte.hu

B Eötvös Loránd University, Faculty of Science, Excellence Center, Brunszvik u. 2. H-2462 Martonvásár, Hungary

* Corresponding author email: dezsozsuzsi@caesar.elte.hu, Telephone: +36-1-372-2500 / 6615, Fax: +36-1-372-2904
} 
mate UHI can result in some benefits, e.g. lower heating costs, less icing and fog, better outdoor comfort, etc. In contrast, in the warm season or in a city with a relatively hot climate, urban heat surplus has mostly negative consequences. Human discomfort, heat stress, higher mortality and increased energy demand of air conditioning can be definitely mentioned as the best-known effects (Stewart and Oke, 2012).

To determine the UHI intensity (Mirzaei and Haghighat, 2010), several temperature variables can be used, e.g., regular air temperature measurements from standard meteorological stations (e.g., Oke, 1973) and/or urban climatological networks (e.g. Šećerov et al., 2019), ground-based air temperature measurements using a moving vehicle (e.g., Unger et al., 200o), surface temperature data measured locally with infrared thermometers (e.g. Doulos et al., 2004) or measured remotely from an aircraft (e.g. Ben-Dor and Saaroni, 1997) or calculated from radiation measurements of satellites (e.g., Price, 1979; Nichol, 2005; Pongrácz et al., 2006). The daily cycles of UHI intensities are different when using the different methods as shown by Roth et al. (1989) or Stoll and Brazel (1992) using Vancouver (from British Columbia, Canada), Seattle (from Washington, USA), Los Angeles (from California, USA), and Phoenix (from Arizona, USA) as examples. Thus, it is very important to highlight whether air or surface temperature is used. The air temperature-based UHI intensity reaches its maximum at night (Oke, 1982), while the maximum of the surface temperature-based UHI (SUHI) occurs in the very early afternoon when the incoming solar radiation is the greatest (Vukovich, 1983).

Several studies have addressed the possibilities of mitigating the SUHI effect in the last few decades. For instance, Doulos et al. (2004) investigated the role of different materials in cooling outdoor urban spaces. The thermal characteristics of 93 commonly used pavement materials were examined using infrared thermography. They found that the main reason of the observed surface temperature differences is the different albedo of the studied materials, which depends on the colour, the surface texture and the construction material. More specifically, rough and dark coloured surfaces are clearly warmer than smooth, flat and light coloured surfaces. Similar results were obtained by Alchapar et al. (2013), who examined the thermal behaviour of pedestrian pavements, tiles and vertical claddings in a semi-arid city. Qin (2015) summarised the benefits and challenges of using cool pavements to mitigate the SUHI effect. This review article categorised the cool pavements into three main groups: (i) reflective pavements, (ii) evaporative pavements, and (iii) pavements with modified heat storage capabilities, e.g. heat-harvesting pavements. Reflec- tive pavements are more appropriate in cities with hot and dry summers. Evaporative pavements are permeable or water-retentive surfaces that produce a cooling effect by evaporating the water stored in the pavement layers (Higashiyama et al., 2016). These pavements are more suitable for regions with a rainy and humid climate, where enough water is available. Heat-harvesting pavements stay cool and harness renewable energy at the same time. However, the use of these methods is still in a development phase because of high costs and open questions about efficiency.

In addition to the use of cool surfaces, vegetation cover also plays a major role in optimising urban thermal conditions. For example, Salata et al. (2015) analysed the combined effect of buildings' materials and vegetation on outdoor thermal comfort. They pointed out that high albedo results in lower surface temperatures, which helps to decrease temperatures in indoor environments, but can negatively affect the psychophysical well-being of pedestrians, especially in areas with low sky view factor. Overall, the most effective tool to support thermal comfort in an urban environment with hot climatic conditions is the presence of vegetation, which is able to decrease both air and surface temperature, particularly by the effect of evapotranspiration and by controlling both the incident and reflected direct shortwave radiation. Shahidan et al. (2012) completed model simulations to investigate the combined cooling effect of trees and ground materials in a tropical city. Their results show that three major factors play an important role in the optimal improvement of both indoor and outdoor environment, namely, the increase of tree quantity, higher tree canopy density and cool ground materials. The role of shading was analysed in the study of Vanos et al. (2016) in a special urban environment, namely, in children's playgrounds. Both natural and artificial shade types (i.e. trees and shade sail, respectively) can substantially reduce surface temperature.

The increasing albedo of urban areas certainly affects thermal conditions on the local scale; moreover, it can potentially compensate for the global warminginduced temperature increase. Akbari et al. (2012) simulated the long-term effect of increasing urban surface albedo using a global climate model. They found that the albedo increases of urban areas in the hot and temperate regions of the world by 0.1 results in a slight global cooling, i.e. a decrease of global mean temperature by $0.01-0.07 \mathrm{~K}$, which corresponds to an emission reduction equivalent to $25-150$ billion tonnes of $\mathrm{CO}_{2}$.

As Muller et al. (2013) summarised, most of the insitu measuring networks consider air temperature and other atmospheric variables, and only a smaller portion of these networks measure surface temperature. For example, Nadeau et al. (2009) analysed the measurements 
during a field campaign in a university campus of Lausanne (Switzerland) from 2006-2007. Although surface temperature was recorded, the main focus of this study was the dynamical processes in an urban environment with special attention to sensible heat flux. Probably the most important example of analysing in-situ measurements of surface temperature involves the Oklahoma MesoNet (Fiebrich et al., 2003), where infrared temperature sensors were used in 89 stations from 1999 to 2001 and revealed several limiting factors, namely, a problem of calibration in cold conditions, the difficult maintenance of remote locations, and the sensors' narrow view (causing limitations in the representation of local conditions). However, the majority of studies (e.g. Lo and Quattrochi, 2003; Rasul et al., 2017, Yavaşli, 2017, Wang et al., 2018) use remotely sensed measurements to analyse and compare surface temperatures in urban environment and rural surroundings, even though only clear sky conditions can be considered. Several studies used satellite measurements for analysing urban effects in Central Europe. For example, Geletič et al. (2019) compared the SUHI of three cities (Prague and Brno from the Czech Republic, and Novi Sad from Serbia) using surface temperatures derived from LANDSAT-8. Dezső et al. (2005) analysed the SUHI of Budapest and other nine Hungarian cities, while Cheval and Dumitrescu (2015) studied the SUHI of Bucharest (Romania) using surface temperature data derived from MODIS (Moderate Resolution Imaging Spectroradiometer) measurements.

This study aims to analyse in-situ surface temperature measurements carried out in late spring and summer over various surface materials of two specific areas in a district of Budapest using an infrared thermometer. First, the measuring sites and the methodology are described, which is followed by the presentation and discussion of results, and finally, the concluding remarks at the end.

\section{Data and methods}

Ujbuda is one of the most dynamically developing districts of the Hungarian capital with more than 130,000 inhabitants (HMI, 2019). Overall, the 23 districts of Budapest have a total of 1,752,286 inhabitants, of which almost $8 \%$ live in Ujjbuda, thus forming the most populated district. The geographical location of the district and the measuring sites is presented in Figure 1. The district is characterised by very diverse land use types: both densely and sparsely built-up residential areas, industrial and commercial areas, road and railway traffic nodes are present as well as parks, forests, lakes and rivers. Recently, major real estate developments have taken place in the district.

The measurements were made with a Voltcraft IR280 infrared thermometer, which has been designed for non-contact temperature measurement. This instrument determines the surface temperature of an object from its emitted infrared energy and its emissivity. The temperature measuring range is from $-30^{\circ} \mathrm{C}$ to $270{ }^{\circ} \mathrm{C}$.

Our urban climate measurement campaigns were organised in the periods of high solar elevation angles, i.e. in late spring and early summer (more specifically, in July 2018, and in May and June 2019) at two measuring sites. The first site is the largest public park of the district, called Bikás Park (Green Park Site), the second site is a busy transportation centre, one of the most densely built-up squares of the city, namely the Móricz Zsigmond Square (Artificial Covered Site). We selected 37 measuring points at the Green Park Site (Figure 2), and 17 measuring points at the Artificial Covered Site (Figure 3). The detailed list with the name and surface materials of these measuring points for both sites can be found in Table 1 and Table 2, respectively. The Green Park Site includes several types of surface cover, both natural and artificial surfaces.

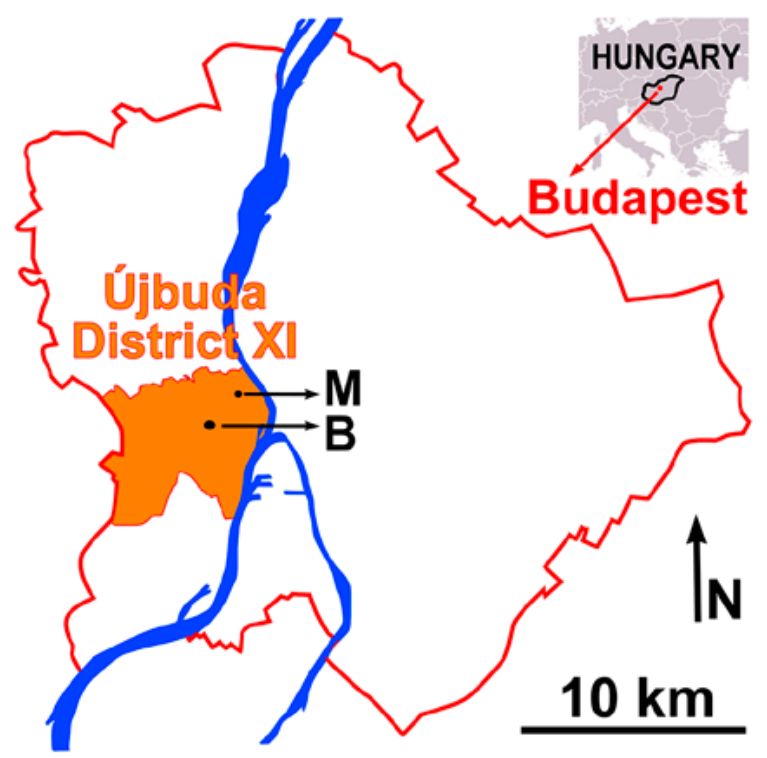

Figure 1. Geographical location of Újbuda (District XI of Budapest) and the measuring sites. M indicates the Móricz Zsigmond Square (Artificial Covered Site), B indicates the Bikás Park (Green Park Site).

The Artificial Covered Site is less diverse in land cover types, and it is dominated by different artificial surface materials (i.e. concrete and asphalt).

During the measurement campaign in 2018 (2-5 July), we carried out measurements four times per day at both sites: at 9 am, 1 pm, 5 pm and 9 pm. Weather conditions were ideal for our purposes with calm, 


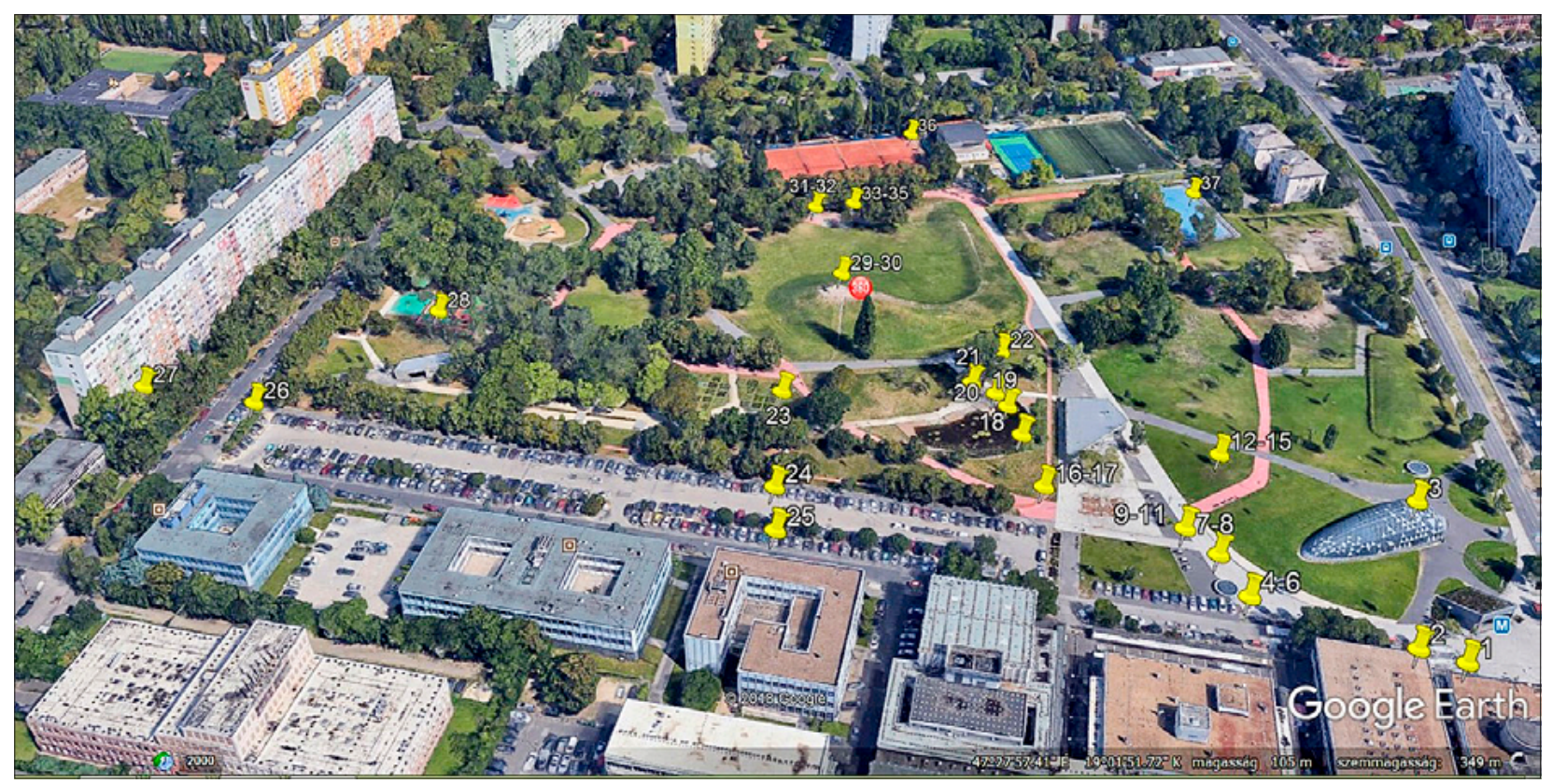

Figure 2. The locations of 37 measuring points (B1-B37) at Bikás Park (Google Earth, 07/2018)

clear, sunny weather, and the time of sunset was 8:43 $\mathrm{pm}$. In the following year, three series of measurements were performed daily at $8 \mathrm{am}, 2 \mathrm{pm}$, and $8 \mathrm{pm}$. The weather was cloudy with shorter sunny periods in some parts of the campaign. The sunset was recorded at 8:16 pm on 17 May, at 8:23-8:26 pm during 23-26
May, and at 8:36-8:37 during 6-7 June. We measured separately the temperature of the different surfaces exposed to direct sunlight and the temperature of the shaded surfaces if both types occurred at the measuring point. Hence, the role of direct sunlight in surface temperature can be examined.

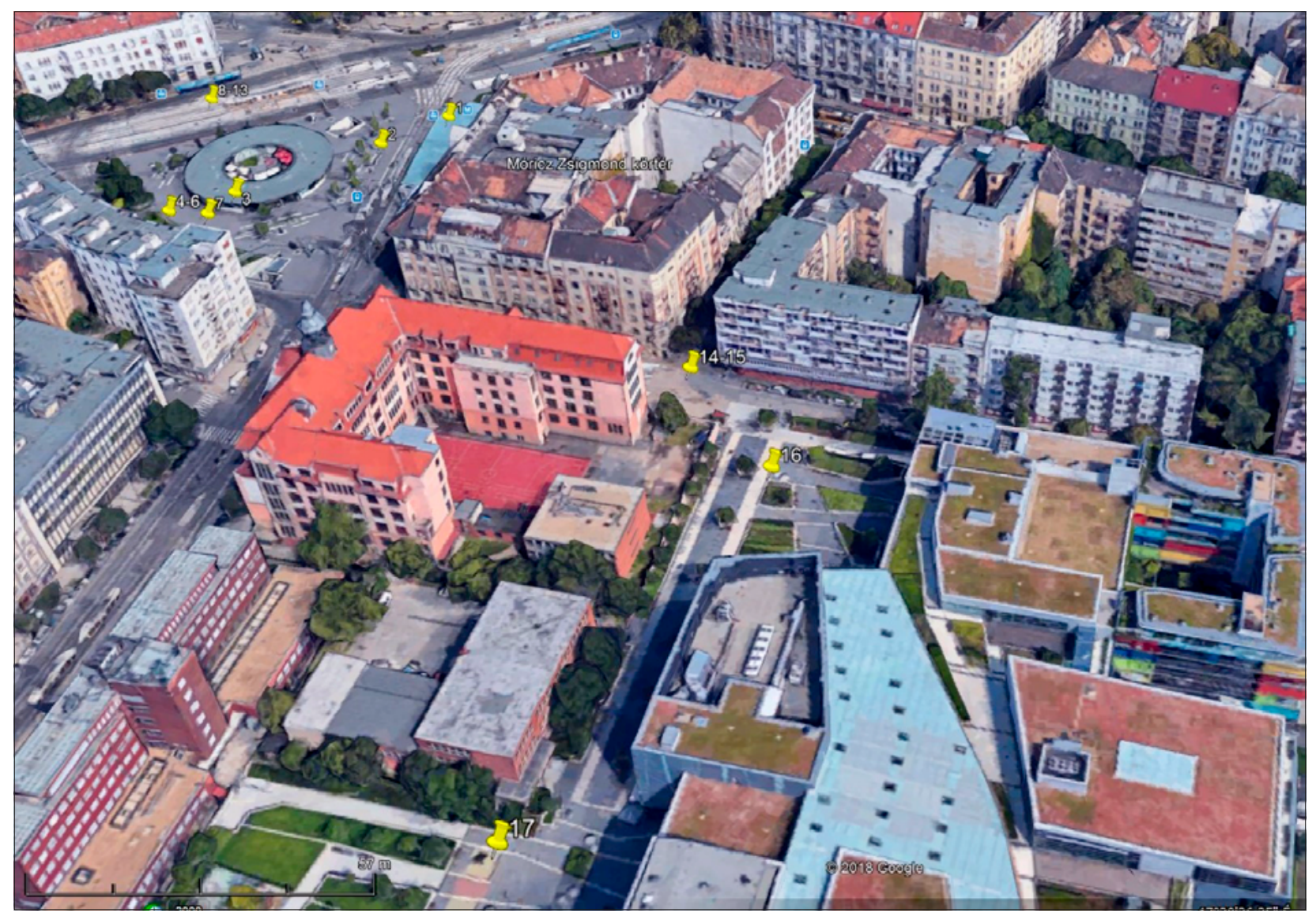

Figure 3. The locations of 17 measuring points (M1-M17) at the Móricz Zsigmond Square (Google Earth, 07/2018) 
Table 1. The list of measuring points and surface materials at Bikás Park

\begin{tabular}{|c|c|c|}
\hline number & description & surface material \\
\hline B1 & market sign & concrete \\
\hline B2 & pillar in the market & metal \\
\hline B3 & subway station building & glass \\
\hline B4 & dark gray pavement blocks & concrete \\
\hline B5 & red pavement blocks & concrete \\
\hline B6 & gray pavement blocks & concrete \\
\hline B7 & dark gray pavement blocks & concrete \\
\hline B8 & light gray pavement blocks & concrete \\
\hline B9 & bench & wood \\
\hline B10 & bench & metal \\
\hline B11 & table & concrete \\
\hline B12 & statue of Grosics & metal \\
\hline B13 & lawn at the statue of Grosics & plant \\
\hline B14 & lawn under the tree & plant \\
\hline B15 & tree & plant \\
\hline B16 & red rubber paving & rubber+polyurethane \\
\hline B17 & red pavement & concrete \\
\hline B18 & reed & plant \\
\hline B19 & lake & water \\
\hline B20 & lake footbridge & wood \\
\hline B21 & gravel pavement & stone \\
\hline B22 & tree & plant \\
\hline B23 & bare soil & soil \\
\hline B24 & stony asphalt road & asphalt \\
\hline B25 & asphalt road & asphalt \\
\hline B26 & shrub & plant \\
\hline B27 & concrete building & concrete \\
\hline B28 & playground pavement & concrete \\
\hline B29 & statue of Bull & metal \\
\hline B30 & bare soil & soil \\
\hline B31 & grey rubber paving & rubber+polyurethane \\
\hline B32 & red rubber paving & rubber+polyurethane \\
\hline B33 & bicycle handlebars & plastic \\
\hline B34 & metal pipe & metal \\
\hline B35 & public workout equipment & metal \\
\hline B36 & tennis court cover & clay \\
\hline B37 & $\begin{array}{l}\text { football field blue rubber } \\
\text { paving }\end{array}$ & rubber+polyurethane \\
\hline
\end{tabular}

\section{Results and discussion}

The aims of this study are to evaluate and to compare the thermal properties of different typical surface covers within urban areas. For this purpose, common statistical tools are performed, i.e. box-and-whiskers diagrams to represent the distribution of surface temperature measurements over a specific surface cover, averaging available measurements to compare different types of surface covers, etc.
Table 2. The list of measuring points and surface materials at Móricz Zsigmond Square

\begin{tabular}{|c|l|l|}
\hline number & description & surface material \\
\hline M1 & subway station building & glass \\
\hline M2 & bench & wood \\
\hline M3 & Bistro wall & concrete \\
\hline M4 & lawn & plant \\
\hline M5 & tree & plant \\
\hline M6 & reed & plant \\
\hline M7 & dark gray pavement blocks & concrete \\
\hline M8 & red pavement blocks & concrete \\
\hline M9 & blue pavement blocks & concrete \\
\hline M10 & gray pavement blocks & concrete \\
\hline M11 & handrail & plastic \\
\hline M12 & tram rail & metal \\
\hline M13 & $\begin{array}{l}\text { asphalt pavement between tram } \\
\text { rails }\end{array}$ & asphalt \\
\hline M14 & road & asphalt \\
\hline M15 & light gray pavement blocks & concrete \\
\hline M16 & bare soil at Allée shopping center & soil \\
\hline M17 & $\begin{array}{l}\text { water surface at Allée shopping } \\
\text { center }\end{array}$ & water \\
\hline
\end{tabular}

To study the thermal properties of various materials, first the mean surface temperature of the noon measurements is determined. Figure 4 and Figure 5 show the results for the Green Park Site and for the Artificial Covered Site, respectively. The upper part of the diagrams (positive direction) represents the average surface temperature values of the surfaces exposed to direct sunlight, while the bottom part (nega- 
tive direction) shows the average temperatures of the shaded parts of the surfaces. In order to facilitate the comparison, different surface materials are represented by different colours. Both diagrams demonstrate clearly that the coolest surfaces are natural covers, i.e. water or vegetation. Even if the surface is exposed to direct sunlight, and thus, absorbs more radiation than from diffuse sunlight only, their surface temperature remains close to the values in case of shaded conditions (the temperature differences between the sunny and shaded surfaces are mostly around $5{ }^{\circ} \mathrm{C}$ ). Bare soil warms up more than vegetation when exposed to direct solar radiation, so it is better to plant vegetation than to leave bare soil surface without any vegetation. The hottest surfaces are clearly the sunny concrete pavements, dark painted wood objects, asphalt and rubber paving. Their average surface temperatures exceed $30^{\circ} \mathrm{C}$ at noon, and even $40^{\circ} \mathrm{C}$ in the case of wood, asphalt and rubber paving. The difference between mean temperatures of sunny and shaded surfaces of each measuring point depends on the properties of the actual surface material. Surface tempera- tures are relatively high, close to $30{ }^{\circ} \mathrm{C}$, in the case of shaded concrete pavements, while direct solar radiation makes the surface temperatures of concrete higher, up to $30-40^{\circ} \mathrm{C}$. Temperature differences are greater for rubber-paved surfaces, namely, the mean temperatures in the shaded areas are between $20^{\circ} \mathrm{C}$ and $30^{\circ} \mathrm{C}$, but these rubber surfaces become extremely hot (over $40^{\circ} \mathrm{C}$ ) when they are exposed to direct radiation.

In the next steps of this study we focused on the thermal differences among the same types of surface covers, so we investigated the role of the colours in case of the concrete paving. For this purpose, four measuring points are selected from the Móricz Zsigmond Square that are close to each other with similar micro scale environments, but different colours. Measuring point M15 is covered by light grey pavement blocks, Mio is grey, M8 is red and M9 is blue. Figure 6 compares the distribution of the surface temperature measurement values of these selected points using a box-and-whisker diagram chart. (All available measurements are used in this analysis whether sunny or shaded.)

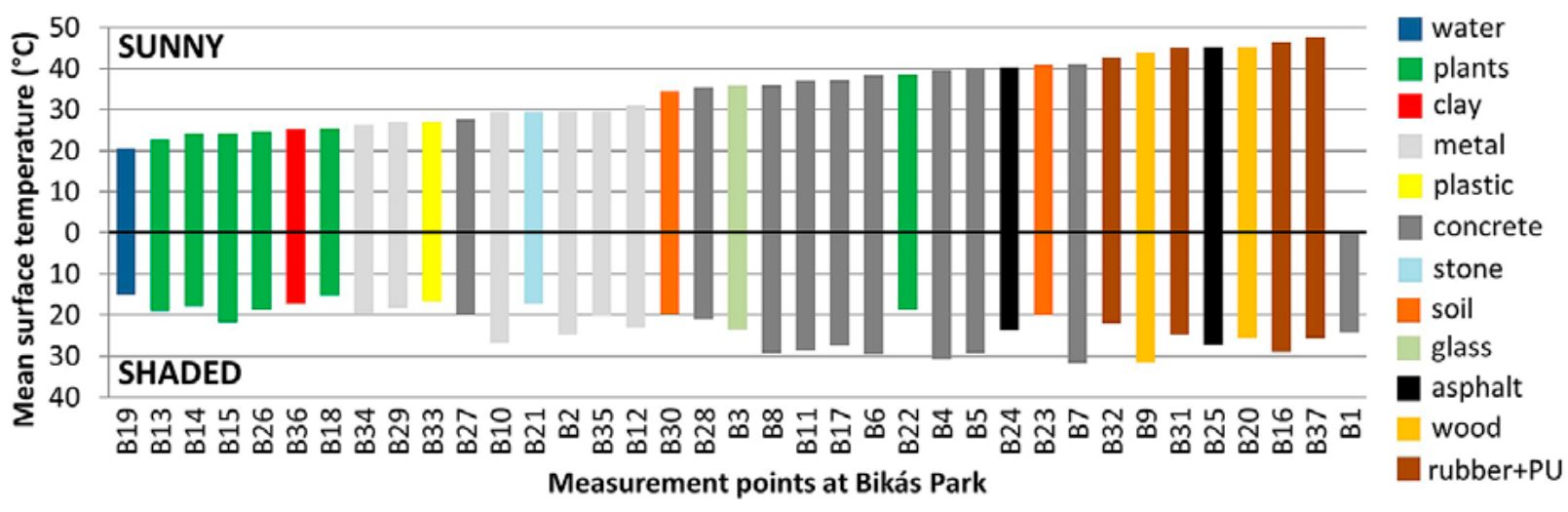

Figure 4. Mean surface temperature of measurements around noon at measuring points in Bikás Park. Colours indicate the surface materials of the points. The upper part of the diagram (positive direction) represents the sunny, while the lower part (negative direction) represents the shaded measurements at the same point

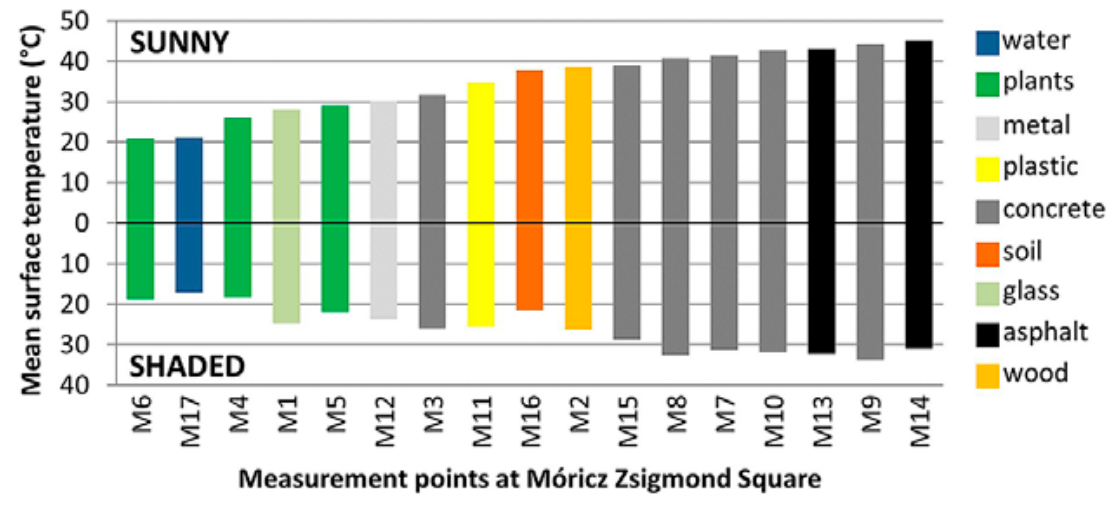

Figure 5. Mean surface temperature of measurements around noon at measuring points in Móricz Zsigmond Square. Colours indicate the surface materials of the points. The upper part of the diagram (positive direction) represents the sunny, while the lower part (negative direction) represents the shaded measurements at the same point 
The light grey pavement clearly shows the lowest temperature values, then, overall, the grey surface is warmer, the red is slightly warmer, and the blue pavement is the hottest. This sequence of temperature ranges clearly suggests that light coloured concrete covers are much better than dark coloured concrete covers from the point of view of how they affect the near-surface atmospheric layers where people can be found. The reason behind this behaviour is certainly the albedo (and consequently, the portions of reflected and absorbed radiations) of the different coloured concretes, i.e. light colours reflect more radiation than dark colours. As the temperature values of sunny surfaces are substantially higher than the temperature of shaded surfaces, the sub-median range of the entire distribution represents the shaded measurements, whereas the above-median range includes mainly the sunny measurements. Despite having more measurements for shaded conditions than sunny conditions, the asymmetry of the distribution shows a positive skewness towards higher temperature. This implies that the variation of sunny temperatures is greater than the variation of shaded temperatures.

As Figure 4 shows, the hottest points in the measurement series are the rubber-paved surfaces exposed to direct radiation. This paving material has lately become very popular in the design of playgrounds, running tracks and sport fields. Various technologies exist for producing these types of surfaces; the most often-used technology consists of the following two main processes, (i) splitting small pieces of vulcanised rubber, and then, (ii) gluing them together with various polyurethane or latex materials. The use of these surfaces has several advantages. For instance, rubber-paved surfaces reduce the risk of injury, it is easy to keep them clean, and they have a modern look. However, from the urban climatological point of view, the use of these covers may also be disadvantageous due to their thermal properties. In addition, volatile organic compounds (VOCs) can be released from these surfaces, and the total emis-

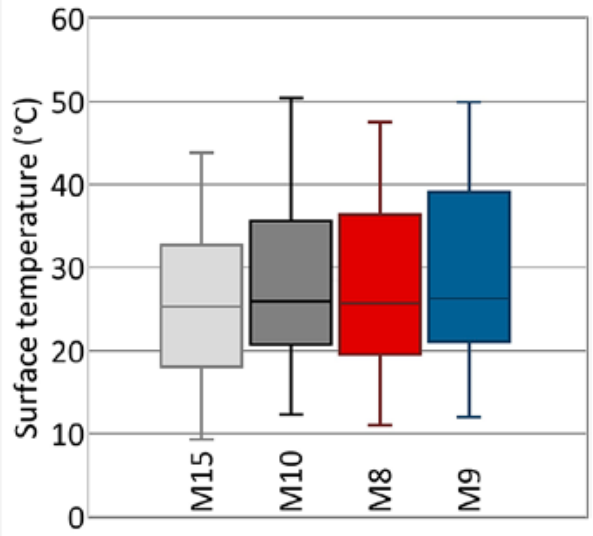

Figure 6. Surface temperature distribution of concrete pavement surfaces of different colours at Móricz

Zsigmond Square. The box-and-whisker diagram includes the minimum and the maximum (bottom and upper end of the whiskers, respectively), the lower and upper quartiles (bottom and top of the box, respectively) and the median (line inside the box) of all the available data. The colours of the pavement blocks: M15 - light grey, M10 - grey, M8 - red, M9 - blue.

sion flux is correlated to the track surface temperature (Chang et al., 1999).

In the last part of this study we focus on these rubber-paved surfaces to evaluate their behaviour in the measuring sites. Figure 7 shows all temperature values for four measuring points covered by rubber paving located at Bikás Park (this surface cover type cannot be found at Móricz Zsigmond Square). The rubber paving materials are similar in these measuring points, but their colours are different, namely, B16 and $\mathrm{B}_{32}$ are red, $B_{31}$ is grey, and $B_{37}$ is blue. Sunny and shaded measurements are compared in this analysis, so different symbols are used for them in the diagram. Evening measurements mostly resulted in data for shaded conditions with very few exceptions. In addition, measurements with sunny conditions are missing on some days (e.g. 23.5.2019) due to cloudy weather. Summer is wellknown for hot periods that can be even more severe in the urban environment. Extreme surface temperatures

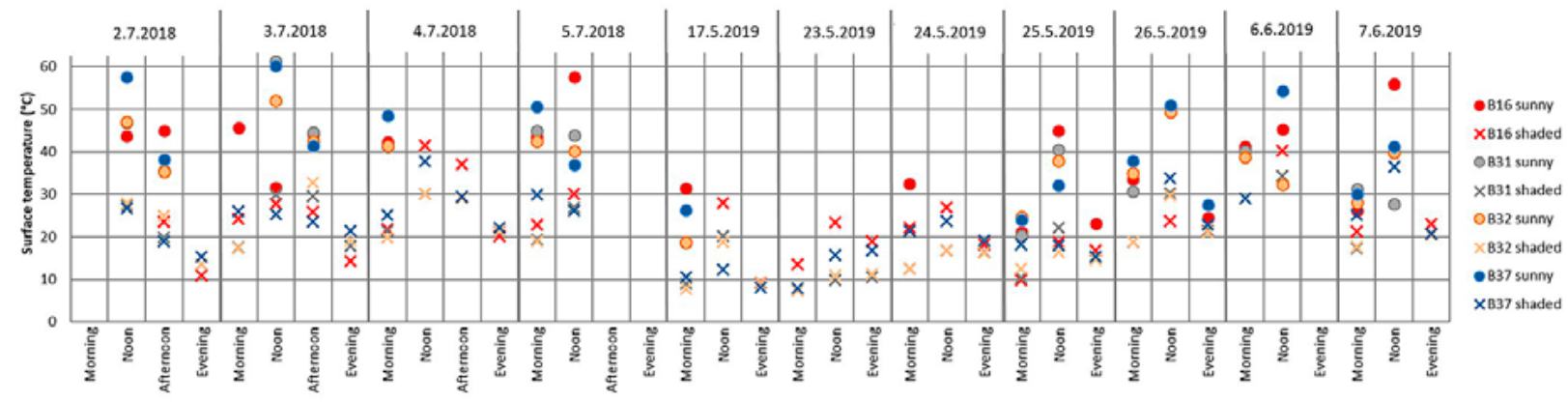

Figure 7. Surface temperature measurements of different rubber-paved surfaces at Bikás Park measuring site. Circles and crosses represent temperatures at sunny and shaded points, respectively. The colours of the rubber surfaces are as follows: B16 - red, B31 - grey, B32 - red, B37 - blue 
can appear during this period of the year, especially in calm, sunny weather conditions. The highest temperature of the present campaigns was measured on 3.7.2018 when the temperature of the grey rubber paving reached $61.2^{\circ} \mathrm{C}$ shortly after noon. Figure 7 clearly shows that there is a distinct difference between sunny and shaded surface temperature values. Shaded temperatures generally remain within tolerable temperature range, they exceed $30{ }^{\circ} \mathrm{C}$ in a few cases only. In contrast, sunny surfaces are often extremely warm (above $40^{\circ} \mathrm{C}$ ). These extreme temperatures have a negative impact on human comfort, so the usability of the facilities (playgrounds, sport fields) covered with this artificial material is strongly limited.

\section{Conclusion}

In the framework of a cooperation between the Urban Climate Research Group of the Department of Meteorology at the Eötvös Loránd University and the Department of Environment at the Municipality of Ujbuda, measuring campaigns were conducted in July 2018 and in May and June 2019 to determine the surface temperature properties of different natural and artificial urban materials using a Voltcraft IR-280 infrared thermometer. The measurements were carried out at two measuring sites: (i) in the largest public park of the district, called Bikás Park (with 37 measuring points), (ii) in the commercial and public transportation centre of the district, called Móricz Zsigmond Square (with 17 measuring points). On the basis of the compiled database, a detailed statistical analysis was performed to investigate the thermal properties of various urban surfaces, e.g. pavements, walls, street furniture, sport facilities, water and plant surfaces.

In this period of the year, extremely high surface temperatures can occur, especially when the surface is directly exposed to sunlight. The average surface temperature measurements around noon exceed $40{ }^{\circ} \mathrm{C}$ in the case of dark painted wood objects, asphalt and rubber-paved surfaces with sunny conditions. In the case of most materials, shading reduces the surface temperature substantially, and consequently, potential thermal stress above these surfaces is decreased effectively.

The coolest surfaces are natural covers, i.e. water and vegetation surfaces. Bare soil surfaces are slightly warmer, which highlights that the planting of vegetation can provide climatic benefits, and overall, it will improve human comfort.

Substantial temperature differences can often be detected among similar surface covers within the same type of materials. Surface colours definitely influence the thermal properties; thus choosing the appropriate colour can effectively reduce the surface temperature. The analysis focusing on the concrete paving blocks with different colours shows that the average surface temperature of light grey surfaces is 5-7 ${ }^{\circ} \mathrm{C}$ lower than the average temperature of darker colours. The difference is more pronounced when the surfaces are exposed to direct sunlight. The reason behind this behaviour is probably the albedo of the different coloured concretes, i.e. light colours reflect more and absorbs less radiation than dark colours. The presented analysis clearly highlights that it is recommended to use light coloured paving blocks instead of dark pavements.

During the measurement series, the highest temperatures (over $50{ }^{\circ} \mathrm{C}$ ) were measured at rubber pavingcovered sport facilities and playgrounds, in sunny conditions. This material is very popular because its use has many benefits. Our study showed that the extensive use of these surfaces has a negative impact on the urban climate. These surfaces warm up so much during sunny summer days that the facilities covered with this material become practically unusable due to their extremely hot surface. In the case of this surface material, shading plays an important role as it can effectively control and reduce the warming of rubber paving-covered surfaces. More specifically, during daytime, the shaded parts of these surfaces are often $20-30{ }^{\circ} \mathrm{C}$ cooler than the sunny surfaces. Therefore, it is highly recommended to use other, natural materials with better thermal properties, e.g. sand and grass for playgrounds. Wherever the alternate natural cover is not possible for any reason, and this rubber paving material is chosen to cover the surface due to its advantageous properties, it is essential to provide potential shading and protect the surfaces from direct sunlight as much as possible, e.g. by planting trees with sufficient foliage around the facilities.

Surface temperature substantially influences the temperature of the near-surface atmospheric layers, and consequently, the overall human comfort. Our study showed that the adverse effects of the urban climate can be effectively mitigated (i) by selecting appropriately the covering materials, (ii) by increasing the proportion of natural vegetation and water surfaces, and (iii) by appropriate shading of surface covers with less advantageous thermal properties.

It is important for urban planning and development professionals to be aware of the role of different surfaces, colours and shading, and to take into account urban climatic factors when making a new investment. Taking the suggestions derived from our results into account can effectively contribute to a more comfortable, healthy and sustainable urban environment. 


\section{Acknowledgements}

Research leading to this paper was supported by the following sources: the Széchenyi 2020 programme, the European Regional Development Fund and the Hungarian Government via the AgroMo project (grant number: GINOP-2.3.2-15-2016-0oo28), the Hungarian National Research, Development and Innovation Fund under grants K-129162 and K-120605, the Bolyai János Fellowship of the Hungarian Academy of Sciences, and the Hungarian Ministry of Human Capacities under the ELTE Excellence Program (grant number: 783-3/2018/FEKUTSRAT). This study is a contribution to the PannEx Regional Hydroclimate Project of the World Climate Research Programme (WCRP) Global Energy and Water Exchanges (GEWEX) Project. In-situ measurements were completed by MSc students of the Eötvös Loránd University (D. Rumpler, A. Berényi, R. Dávid, D. Incze, D. Nagy, V. Szalai, D. Topál, A. Tóth).

\section{References}

Akbari, H., Matthews, H. D., \& Seto, D. (2012). The long-term effect of increasing the albedo of urban areas. Environmental Research Letters, 7(2), 024004. DOI:10.1088/1748-9326/7/2/024004

Alchapar, N. L., Correa, E. N., \& Cantón, M. A. (2014). Classification of building materials used in the urban envelopes according to their capacity for mitigation of the urban heat island in semiarid zones. Energy and Buildings, 69, 22-32. DOI:10.1016/j. enbuild.2013.10.012

Ben-Dor, E., \& Saaroni, H. (1997). Airborne video thermal radiometry as a tool for monitoring microscale structures of the urban heat island. International Journal of Remote Sensing, 18(14), 3039-3053. DOI: 10.1080/014311697217198

Baniassadi, A., Sailor D.J., \& Ban-Weiss, G.A. (2019). Potential energy and climate benefits of super-cool materials as a rooftop strategy. Urban Climate, 29, 100495, DOI: 10.1016/j.uclim.2019.100495.

Chang, F. H., Lin, T. C., Huang, C. I., Chao, H. R., Chang, T. Y., \& Lu, C. S. (1999). Emission characteristics of VOCs from athletic tracks. Journal of hazardous materials, 7o(1-2), 1-20. DOI: 10.1016/S03043894(99)oo154-5

Cheval, S., \& Dumitrescu, A. (2015). The summer surface urban heat island of Bucharest (Romania) retrieved from MODIS images. Theoretical and Applied Climatology, 121, 631-640. doi: 10.1007/ s00704-014-1250-8

Dezső, Zs., Bartholy, J., \& Pongrácz, R. (2005). Satellite-based analysis of the urban heat island effect. Idójárás/Quarterly Journal of the Hungarian Meteorological Service, 109(4), 217-232.

Doulos, L., Santamouris, M., \& Livada, I. (2004). Passive cooling of outdoor urban spaces. The role of materials. Solar energy, $77(2), 231-249$. DOI: 10.1016/j. solener.2004.04.005

Fiebrich, C.A., Martinez, J.E., Brotzge, J.A., \& Basara, J.B. (2003). The Oklahoma Mesonet's skin temperature network. Journal of Atmospheric and Oceanic Technology, 20(11): 1496-1504. DOI: 10.1175/1520-0426(2003)020<1496:TOMSTN>2.0. $\mathrm{CO} ; 2$

Geletič, J., Lehnert, M., Savić, S. and Milošević, D. (2019). Inter-/intra-zonal seasonal variability of the surface urban heat island based on local climate zones in three central European cities. Building and Environment, 156, 21-32. doi: 10.1016/j.buildenv.2019.04.011

Higashiyama, H., Sano, M., Nakanishi, F., Takahashi, O., \& Tsukuma, S. (2016). Field measurements of road surface temperature of several asphalt pavements with temperature rise reducing function. Case Studies in Construction Materials, 4, 73-80. DOI: 10.1016/j.cscm.2016.01.001

HMI (2019): Hungarian Ministry of Interior, https:// nyilvantarto.hu/hu/statisztikak?stat=kozerdeku

Lo, C.P., \& Quattrochi, D.A. (2003). Land-use and land-cover change, urban heat island phenomenon, and health implications: A remote sensing approach. Photogrammetric Engineering and Remote Sensing, 69, 1053-1063. DOI: 10.14358/PERS.69.9.1053

Mirzaei, P. A., \& Haghighat, F. (2010). Approaches to study Urban Heat Island - Abilities and limitations. Building and Environment, 45, 2192-220. DOI: 10.1016/j.buildenv.2010.04.001

Muller, C.L., Chapman, L., Grimmond, C.S.B., Young, D.T., \& Cai, X-M. (2013). Sensors and the city: a review of urban meteorological networks. Int. J. Climatol. 33, 1585-160o. DOI: 10.1002/joc.3678

Nadeau, D.F., Brutsaert, W., Parlange, M.B., Bou-Zeid, E., Barrenetxea, G., Couach, O., Boldi, M.-O., Selker, J.S., \& Vetterli, M. (2009). Estimation of urban sensible heat flux using dense wireless network of observations. Environmental Fluid Mechanics, 9, 635-653. DOI: 10.1007/s10652-009-9150-7

Nevat, I., Ruefenacht, L.A., \& Aydt, H. (2020). Recommendation system for climate informed urban design under model uncertainty. Urban Climate, 31, 100524, DOI: 10.1016/j.uclim.2019.100524 
Nichol, J. (2005). Remote sensing of urban heat islands by day and night. Photogrammetric Engineering and Remote Sensing, 71, 613-621. DOI:

Oke, T. R. (1973). City size and the urban heat island. Atmospheric Environment, 7(8), 769-779. DOI: 10.1016/0004-6981(73)90140-6

Oke, T. R. (1982). The energetic basis of the urban heat island. Quarterly Journal of the Royal Meteorological Society, 108(455), 1-24. DOI: 10.1002/ qj. 49710845502

Pongracz, R., Bartholy, J., \& Dezso, Z. (2006). Remotely sensed thermal information applied to urban climate analysis. Advances in Space Research, 37(12), 2191-2196. DOI: 10.1016/j.asr.2005.06.069

Price, J.C. (1979). Assesment of the heat island effect through the use of satellite data. Monthly Weather Review, 107, 1554-1557. DOI: 10.1175/1520-0493(1979)107<1554:AOTUHI>2.0.CO;2

Qin, Y. (2015). A review on the development of cool pavements to mitigate urban heat island effect. $R e$ newable and sustainable energy reviews, 52, 445-459. DOI: 10.1016/j.rser.2015.07.177

Rasul, A., Balzter, H., Smith, C., Remedios, J., Adamu, B., Sobrino, J.A., Srivanit, M., \& Weng, Q. (2017). A Review on Remote Sensing of Urban Heat and Cool Islands. Land, 6, 38. DOI: 10.3390/land6020038

Roth, M., Oke, T.R., \& Emery, W.J. (1989). Satellitederived urban heat islands from three coastal cities and the utilization of such data in urban climatology. International Journal of Remote Sensing, 10, 1699-1720, DOI: 10.1080/01431168908904002

Salata, F., Golasi, I., de Lieto Vollaro, A., \& de Lieto Vollaro, R. (2015). How high albedo and traditional buildings' materials and vegetation affect the quality of urban microclimate. A case study. Energy and Buildings, 99, 32-49. DOI: 10.1016/j.enbuild.2015.04.010

Šećerov, I.B., Savić, S.M., Milošević, D.D., Arsenović, D.M., Dolinaj, D.M., \& Popov, S.B. (2019). Progressing urban climate research using a high-density monitoring network system. Environmental Monitoring and Assessment, 191, 89-. https://doi. org/10.1007/s10661-019-7210-o
Shahidan, M. F., Jones, P. J., Gwilliam, J., \& Salleh, E. (2012). An evaluation of outdoor and building environment cooling achieved through combination modification of trees with ground materials. Building and Environment, 58, 245-257. DOI: 10.1016/j. buildenv.2012.07.012

Stewart, I. D., \& Oke, T. R. (2012). Local climate zones for urban temperature studies. Bulletin of the American Meteorological Society, 93(12), 1879-1900. DOI: 10.1175/BAMS-D-11-00019.1

Stoll, M.J., \& Brazel, A.J. (1992). Surface-air temperature relationships in the urban environment of Phoenix, Arizona. Physical Geography, 13(2),160179. DOI: $10.1080 / 02723646.1992 .10642451$

Sundborg, Å. (1950). Local climatological studies of the temperature conditions in an urban area. Tellus, 2(3), 222-232. DOI: 10.3402/tellusa.v2i3.8544

Unger, J., Bottyán, Z., Sümeghy, Z., \& Gulyás, Á. (2000). Urban heat island development affected by urban surface factors. Idoojárás/Quarterly Journal of the Hungarian Meteorological Service, 104, 253-268.

Vanos, J. K., Middel, A., McKercher, G. R., Kuras, E. R., \& Ruddell, B. L. (2016). Hot playgrounds and children's health: a multiscale analysis of surface temperatures in Arizona, USA. Landscape and Urban Planning, 146, 29-42. DOI: 10.1016/j.landurbplan.2015.10.007

Wang, Y.-C., Hu, B.K.H., Myint, S.W., Feng, C.-C., Chow, W.T.L., \& Passy, P.F. (2018). Patterns of land change and their potential impacts on land surface temperature change in Yangon, Myanmar. Science of The Total Environment, 643, 738-750. DOI: 10.1016/j.scitotenv.2018.06.209

Yavaşli, D.D. (2017). Spatio-Temporal Trends of Urban Heat Island and Surface Temperature in Izmir, Turkey. American Journal of Remote Sensin. 5, 2429. DOI: $10.11648 /$ j.ajrs.20170503.11

Zen, I.S., Al-Amin, A.Q., \& Doberstein, B. (2019). Mainstreaming climate adaptation and mitigation policy: Towards multi-level climate governance in Melaka, Malaysia. Urban Climate, 30, 100501, DOI: 10.1016/j.uclim.2019.100501. 